\title{
An Emergent Framework for Digital Memorials
}

\author{
Wendy Moncur \\ University of Dundee, \\ Dundee, UK \\ wmoncur@dundee.ac.uk
}

\begin{abstract}
Memorialization is a ubiquitous human practice, which is increasingly intersecting with our digital lives. It is becoming ever more commonplace to see discussions and examples of digital memorials in research literature, technology shows and art galleries. However, the design space for digital memorials has, to date, been little explored. In this paper, we propose an emergent framework for digital memorials, based around notions of actors, inputs, form and message. The framework is grounded in examples of current memorialization practice, and situated within a contextual understanding of memorials as an emergent digital phenomenon within a networked society. In detailing the framework we highlight features of the design space that can be exploited in the development of bespoke memorial technologies, and identify potential areas of future interest that this framework brings to the fore, such as HCI's engagement with critical concepts of the postself and temporality.
\end{abstract}

\section{Author Keywords}

Memorial; Memorialization; Thanatosensitive Design; Death; End of Life; Life events.

\section{ACM Classification Keywords}

H.5.m. Information interfaces and presentation (e.g., HCI): Miscellaneous.

\section{INTRODUCTION}

Memorialization, the act of marking a physical or conceptual space for posterity in remembrance of a person or an event, serves as a "bulwark against the terror of forgetting" [15]. It is an act so fundamental to human society that it has been used to recognize the earliest vestiges of human civilization [34]. It is something with which we are all intimately familiar, and yet commonly overlook. Yet memorialization is ubiquitous to our experience of humanity and therefore of interest to experience-centered designers.

Permission to make digital or hard copies of part or all of this work for personal or classroom use is granted without fee provided that copies are not made or distributed for profit or commercial advantage and that copies bear this notice and the full citation on the first page. Copyrights for third-party components of this work must be honored. For all other uses, contact the owner/author(s). Copyright is held by the author/owner(s).

DIS 2014, June 21-25, 2014, Vancouver, BC, Canada.

ACM 978-1-4503-2902-6/14/06.

http://dx.doi.org/10.1145/2598510.2598516

\author{
David Kirk \\ Culture Lab, \\ Newcastle University, \\ Newcastle-upon-Tyne, UK \\ david.kirk@newcastle.ac.uk
}

The ubiquity of the memorial is bound up with cultural modes of practice, which dictate how we might orient to memorials, how we acknowledge them, sanctify them and interact with them $[40,46]$. It is also influenced by how individuals and groups understand the experience of bereavement, even within the same cultural group. For some bereaved individuals, memorialization may help them to leave the dead behind, whilst others may look to memorialization to assist in maintaining a continuing bond with the dead [48].

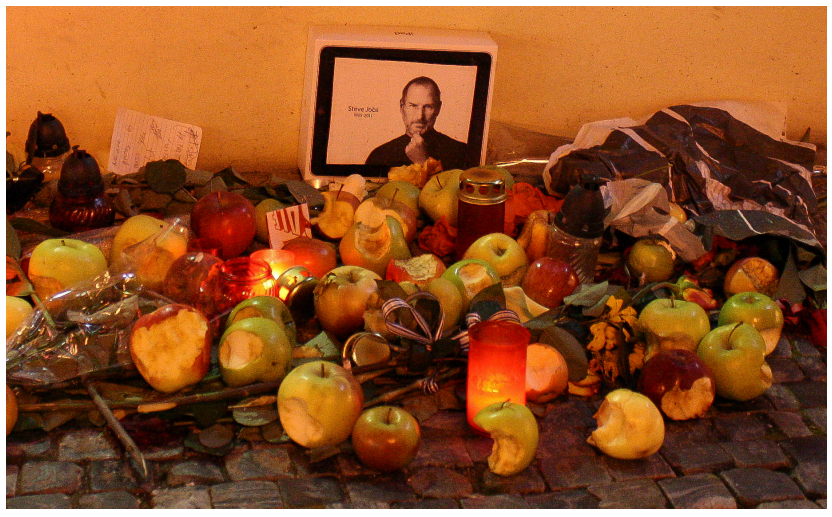

Figure 1. Steve Jobs memorial ${ }^{1}$

Whilst recognizing these cultural and personal variations, in this paper we draw together an understanding of what a memorial might be and how it might work. Different types of artifact and event can be framed as a memorial, and we acknowledge that they might be emergent, dynamic or use irregular materials. For example, one might compare very traditional (to some cultures) marble gravestones with the impromptu memorials that appeared outside Apple stores worldwide, with piles of bitten apples, when Steve Jobs passed away (see figure 1).

Concerns for memorialization become shot through with concerns for just how use of digital technology might be incorporated into the memorialization process, as our lives increasingly incorporate a digital dimension as part of what Castells conceptualizes 'the network society' [7], and Negroponte frames as 'Being Digital' [30]. These concerns are emerging in the popular imagination as a direct result of the proliferation of Social Network Sites (SNS) and virtual

${ }^{1}$ Photo: http://lifeofriles.com/prague/ 
communities, and of transgressions of emergent social rules around online responses to news of death $[6,19]$.

We have also begun to see the emergence of the application of digital technologies in practices and rites of death. This blurring of physical/ digital boundaries has spanned from the conceptual [3] to the more pragmatic [25]. Research specifically within the HCI and CSCW communities has started to enter this space, with calls for consideration of the End of Life (EOL) as a specific event in the lifespan worthy of dedicated focus [23,24,25], and an exploration of issues such as bequeathing [31], social networking and afterlives [5], digital support for grieving [22], and the continued existence of personal data after the end of physical life [26].

\section{Framing questions for designers}

Despite this emergent seam of work, and a developing concern for 'thanatosensitive design', mapping of the digital memorial design space has been limited [23]. For example, [13] focuses explicitly on web-based memorialization, [12] describes the application of reflective design to digital memorials, whilst [36] considers the use of digital memorials and online grief as a form of entertainment, and [27] considers methodological issues around the wellbeing of researchers working in this area. In mapping this space comprehensively, we seek to answer questions that have arisen in our own continuing work, in contexts ranging from the creation of bespoke personal memorials to the curation of a human rights media archive in Rwanda [10]. The breadth of memorials discussed highlights the many different scales of interaction, and the huge resource of design possibilities available.

Who are the actors involved in digital memorials?
Authors
Audience
What are the Inputs?
Subject and circumstance
Content
Digital forms
Static $<->$ Evolving
What form does the memorial take?
What Message should the memorial convey?
Intentionality: Cultural $<->$ Personal
Sacred $<->$ Secular

Figure 2: Framework summary

We first frame a series of questions for designers to pose when designing digital memorials, and lay out the set of choices available. We then give some examples of the effects of making those choices. In doing so, we tentatively offer an emergent framework for digital memorials within western societies, comprised of dimensions that can be leveraged to give structure to a digital memorial, with consequent impacts on the user experience. This framework is divided here into four main categories: actors, inputs, form and message. A summary is provided in Figure 2. Specific references are given to examples we have found amongst the research community (and in galleries and exhibitions). We situate the emergent qualities of digital memorials within the more established qualities of (nondigital) memorials, providing parallels drawn from the literature. In developing this framework, we hope to help sensitize experience-centered designers to features of the design space that they can exploit in the development of bespoke memorial technologies. We conclude with a discussion of the framework, and by pointing to emerging areas of future work that are raised.

\section{WHO ARE THE ACTORS INVOLVED IN DIGITAL MEMORIALS?}

The actors who have agency in the construction, ownership and use of a digital memorial can be broadly split into two categories: authors and audiences. We consider the composition of each subcategory in turn.

\section{Authors}

A memorial is brought into being by its author(s). The significance of a mourned person, place or event is itself lost over time unless some action is taken to memorialize. Authorship and narrative voice are intrinsically linked, with the author adopting a strongly curatorial role: the nature of the memorial is directly affected by decisions of what to include in the story - and what to leave out. A memorial may be authored by an institution, multiple authors, an individual, or even by the deceased in a process of selfmemorialization in advance of their death. Use of a single narrative voice brings with it inevitable restrictions on perspective. Use of multiple narrative voices acts as heteroglossia [11], providing different views on the same content or acting on multiple (perhaps conflicting) levels e.g. [9]. Inevitably, the message conveyed by a memorial will be shot through with the intentions of its author(s). Negotiating the message of multiple narrative memorials offers many challenges. Who has the right to construct and curate? How does the memorial give visibility to multiple accounts? How does the memorial retain its respect for one set of recollections whilst dealing with alternative accounts? These are challenges that must be addressed in the design process. Such memorial encounters are heavily colored by issues of veracity, and by what it means to represent the accounts of the deceased as 'true'.

A range of authorships can be seen in the memorials created in response to the terrorist attacks carried out in the US on September 11, 2001 (widely referred to as 9/11). The largest institutional memorial is The National September 11 Memorial, which aims to represent the loss experienced by the nation with a consistent, unified narrative voice. It 
incorporates digital elements such as a website, mobile app, and digitally recorded oral histories of those directly affected $^{2}$. Content is ultimately controlled by the Foundation responsible for the Memorial. In contrast, The September 11 Digital Archive $^{3}$ represents multiple (sometimes conflicting) narrative voices in a more heterogeneous collective memorial created by multiple authors and, importantly here, curated by multiple organizations. The Archive contains over 40,000 emails and other electronic communications, 40,000 first-hand stories, and 15,000 digital images. A single author composed the musical piece "E pluribus unum", whilst incorporating digital audio clips from the testimonies of many witnesses and first responders ${ }^{4}$. It thus curates the narrative voices of many into a new single voice. Of course, many informal digital memorials also exist, with individual or multiple (small group) authorship: for example, the online memorial to Father Mychal Judge ${ }^{5}$. Such examples are commonly produced by bereaved family and friends. In these instances, digital technology provides tools to allow for individual expression of grief - although such expressions are limited by the extent of the tools provided.

Less relevant to the context of $9 / 11$ (but important to include here for completeness) is the practice of selfmemorialization. This practice extends back through history, exemplified by the pyramid tombs built by Egyptian pharaohs. We are now seeing examples of digital self-memorialization, where an individual uses digital content and delivery mechanisms to author their own memorial, pre-mortem. Self-memorialization creates the opportunity for the individual to influence how they are remembered. It can extend the social life of the individual beyond physical death as their communication with the living continues on, influencing the nature of the continuing bond created with loved ones after death and the ongoing narrative of memory and reputation which remains after physical life ends [26]. Such memorials may be authored by an individual - e.g. "If I Die" ${ }^{6}$ is a Facebook plugin service, which allows individual account holders to record and archive a video or text testimony that is triggered upon the user's death, by the collective action of three nominated trustees. Opportunities also exist for the co-construction of a memorial to oneself. E.g. the UK charity Rosetta Life $^{7}$ runs creative projects enabling hospice-users to collaborate with artists in telling their story. Resulting artworks such as films and poems are shared with the bereaved, and also placed in a public archive, creating a memorial with both private and public dimensions. Co-construction can be vital

\footnotetext{
2 http://www.911memorial.org/.

3 http://911digitalarchive.org/index.php

${ }^{4}$ http://bit.ly/1gnSfJB

5 http://bit.ly/18ofZs7

6 http://www.ifidie.net/

7 http://www.rosettalife.org/
}

for those who are terminally ill, as they may lack the energy to undertake such tasks alone.

In summary, digital memorials may be authored by an institution, multiple authors, an individual, or even by the deceased in advance of their death. The role of author includes the provision and curation of content, and the delivery of a narrative voice. Creation of (and interaction with) a digital memorial may free the author from the constraints of established social and cultural obligations which exist offline [19], but the extent of the memorialization will inevitably be bounded by the tools provided. Support for use by multiple concurrent authors is currently lacking in such tools.

\section{Audience}

Just as a memorial must be created in order to exist, so it must also be 'consumed' by an audience. The audience for a memorial is situated on a spectrum from public to private, and may change over time.

National memorials are usually authored by an institution, designed to assist a public audience to "make sense of national tragedy" [8], acknowledging a public sense of loss. The Vietnam Veterans Memorial in Washington DC commemorates lives lost in conflict, through physical and digital $^{8}$ elements. Whilst public by design and intention, it incorporates a more private dimension when experienced by those for whom the loss has direct personal significance - such as widows, and military veterans remembering fallen comrades [11]. This private dimension is likely to fade over time, as the bereaved themselves pass away, leaving a persistent public remembrance of societal loss. Spomenik is a digital national memorial that commemorates the victims of the post-World War II Stalinist purges which were conducted in the former Yugoslavia. The memorial consists of survivor testimony which is accessible to the public via mobile phones at a mass gravesite in the Slovenian woods [17]. Whilst the experience of the memorial is public, with an audience that can be seen listening to testimonies at the site, it retains features of an intimate interaction, as the delivered audio content is discrete and personalized.

Informal memorials such as roadside shrines and memorial benches are created by individuals or small groups, and have a public audience [20]. Those with content that directly addresses the deceased serve to (a) communicate private loss in order to affirm the life of the deceased and declare a continuing bond with them, and (b) invite the public to act as witnesses to this abiding affection. Similar memorials which do not directly address the deceased are used by the bereaved to commemorate the dead in a public space, seek empathetic connection with bereaved others, and rewrite personal narratives of the dead. Both types can divide opinion amongst their public audience, exposing sensibilities around whether death and grief are public, or

\footnotetext{
${ }^{8}$ http://www.virtualwall.org/
} 
deeply private experiences which should be sequestrated [45].

Dutch home shrines illustrate the entirely private nature of some memorials. These home-based memorials are intended predominantly for the members of the household. They serve to memorialize one or more significant others including parents, siblings, even pets through the use of permanent and ephemeral personal artifacts [47]. Similarly, the digital family altar "ThanatoFenestra" uses photos in combination with ephemeral artifacts to support personal ritual [39]. The altar displays images of the deceased, interactively linked to the movement of a (real) candle, and is grounded in Buddhist traditions of cleansing spirits.

Web 2.0 has impacted strongly on attitudes to who the audience for a memorial should be. Memorialization of deceased users through online social network sites makes death and grief hard to avoid [43]. Personal memorials abound that are to some degree publicly accessible online. Eulogies of dead loved ones can reach a larger audience and achieve greater longevity online compared to that achieved via obituary pages in the newspapers - e.g. the actor Kevin Costner's eulogy to the singer Whitney Houston at her funeral has reached over 2.5 million viewers via YouTube 9 However, unlike some offline memorials, the online 'public' audience can be controlled by privacy settings: whilst the general public cannot gain access to a memorialized Facebook page, an extended personal social network can. These same privacy controls and settings can conversely (and ironically) block those close to the deceased from accessing the same pages, if they were not already 'friends' online prior to memorialization. In summary, digital memorials can be expected to operate at various levels from the entirely private and domestic to the completely public and national, with various points in between wherein they might be privately created and curated but have levels of openness to public observation and/or contribution. The audience for a memorial may evolve over time, as personal relevance fades yet public significance continues.

\section{WHAT ARE THE INPUTS?}

The inputs to a memorial can be divided into subject, circumstance and content. Whilst subject and circumstance are dictated by past events, content is controlled by authorial curation.

\section{Subject and circumstance}

The ostensible subject of a memorial may be the life of one or more people, an event, or even a place. Integral to any memorial is a sense of life lived, and of loss. An exemplar of place can be seen in the online memorial to the former city of Pinepoint ${ }^{10}$ in Canada. After closure of the local

\footnotetext{
${ }^{9} \mathrm{http}: / /$ www.youtube.com/watch?v=2wjh0N1EzPI

$10 \mathrm{http}: / /$ pinepointrevisited.homestead.com/Pine_Point.html. http://pinepoint.nfb.ca/\#/pinepoint
}

mine, the city was closed in 1988, the buildings removed and the residents asked to leave. A community-supported and curated web-archive and an interactive web documentary provide points of access for the memories of former residents of the city, who are now dispersed across the country. The memorial mediates the memories of former inhabitants, recalling not only the city, but also residents' lives unique to that time and place.

The circumstances under which a memorial is brought into being have an understandable influence on its qualities. Was the loss expected/ unforeseen, timely/ premature, tragic/ traumatic? The unforeseen, premature death of Princess Diana was followed by an unprecedented tide of informal, personal and emotion-laden memorials outside her home and across the UK, made of ephemeral items flowers, messages, and teddy bears [44]. Tragic/ traumatic events can lead to the creation of memorials that have much greater permanence. In Rwanda for example, in the aftermath of the 1994 Genocide, and in an effort at reconciliation and nation rebuilding, digital repositories of survivor testimony were (and are being) collected and made publicly available, to bear witness to the memory of the deceased $^{11}$. Such event-based memorials present design challenges related to their potentially multi-generational nature. What information should be passed forwards across generations? Friedman et al suggest that carefully designed content can be used to avoid future recurrence of (memorialized) atrocities [14]. Further, consideration must be given to how the site of the memorial will engage with communal feelings of loss and suffering over multiple generations for those living in these locations. One area of potential strength for digital memorials (as opposed to more traditional physical memorials) in this context is that they can adapt more easily over time in response to changing circumstances and the requirements of those who engage with them - especially where there is a community in control of the memorial, as data (reflections etc.) as input continually modifies the nature of the memorial.

\section{Content}

Content selected for inclusion in a memorial by the author(s) may include:

- Material possessions of the memorial's subject

- Memories/ testimonies provided by the living

- Material elements of the subject

Material possessions of the subject that are incorporated into a memorial serve to both represent the subject and to have a central place in the mourning process. Mundane objects - including those relating to the funeral, death notices, and digital artifacts [29] - can take on sacred qualities, as they are imbued with emotional and symbolic meaning through their power to invoke memories of the dead. Arnon's Digital Cemetery holds the personal data of

\footnotetext{
11 www.genocidearchiverwanda.org.rw/
} 
the deceased on memory sticks (Figure 3). This data is accessible to family and friends, intended as a place to mourn and remember the dead, much like a real cemetery, which it visually echoes. Such objects serve to establish the identity of the 'postself' - the socially constructed identity of the individual after death - through a process of curation and reflection [47].

Along with the possessions of the dead, memories of the living may be incorporated into a memorial - for example, the Sonic Memorial stores audio testimony from survivors of the events of 9/11 [8]. Incorporation of artifacts belonging to the living is seen most commonly in memorials with a public dimension - perhaps because in private memorials, the narrative voice of survivors has less need to be externalized.

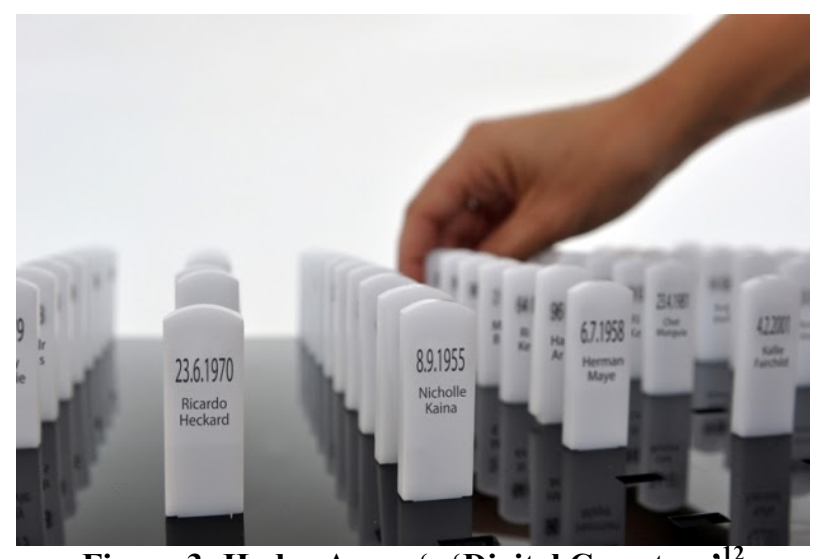

Figure 3: Hadas Arnon's 'Digital Cemetery' ${ }^{, 2}$

When material elements of the subject are incorporated into a memorial (often termed a reliquary in this context), sacred qualities may be intensified [33]. Research such as [25] highlights the combined use of digital photos of the dead (or their favorite place) and cremated remains as inputs into the creation of personalized memorial artworks. Offline, Nadine Jarvis' produces pencils that contain cremated remains, foil stamped with the name of the deceased (Figure 4). Through mundane use, the pencils maintain an intimate and potent link with the deceased. A sealed box with a pencil sharpener stores pencil shavings, becoming a final repository/ urn for the cremated remains ${ }^{13}$. In contrast to such deeply personal memorials, the 'Tomb of the Unknown Warrior' ${ }^{14}$ in London, UK, contains the body of an unknown soldier. By virtue of it containing an unknown body, the memorial comes to stand in proxy for the bodies of each and every unknown victim of the conflict. Here, what is important is the body, and not the individual person.

\section{WHAT FORM DOES THE MEMORIAL TAKE?}

Memorials take forms which we can experience through our senses - sight, touch, sound, even taste and smell. The two-

\footnotetext{
12 Photo: designfetish.org

13 http://bit.ly/YtuMh

${ }^{14}$ http://bit.ly/9c1rOu
}

minute silence to remember the dead on Armistice Day is imbued with significance, even though it lacks a physical instantiation. The scent of incense sticks and the sight of burning candles can be integral to an act of memorialization $[39,47]$. Digital technologies present increased opportunities to create memorials in new forms, along three dimensions: physical-digital, central-distributed, concreteperformative. The form of a memorial may be static, or it may evolve over time, actively or passively.

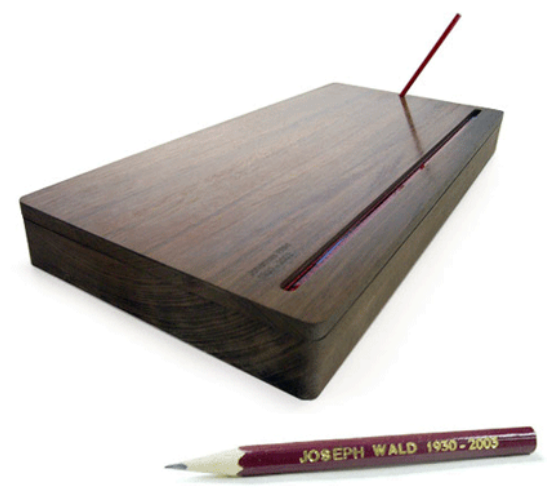

Figure 4: Pencils \& 'urn' containing cremated remains ${ }^{15}$

\section{Digital forms}

A digital memorial may be wholly digital, or hybridized to incorporate physical elements. In Second Life, the wholly digital Palestinian Holocaust Memorial Museum featured photos, names and stories of Palestinian children allegedly killed by Israeli forces [38]. In contrast, Gauler's Digital Remains provides a physical key to access the digital remains of a loved one (figure 5). The Scan Memories ${ }^{16}$ project produced memorials in a geographically distributed form, whilst also incorporating physical and digital elements. Memories were stored digitally, but the bereaved accessed them in specific, meaningful physical locations, through use of a trail of geographically distributed RFID tags.

A memorial can take a concrete form, through a dedicated instantiation that redacts physical or virtual space. Both standard western Christian graves marked by a headstone and cyber-graves as seen in Second Life [16] are concrete. Associated with this concrete form, mementoes left at the site can highlight the location of a memorial and provide a focus for visits. Such mementoes can also help to maintain connections with the dead and to honor them [48].

Rituals of gesture, action or spoken words lend a performative form to a memorial, acting as a signifier through which a private bond with the dead can be achieved [15]. Such rituals may be ones of inaction as well as action - for example, the Aboriginal tradition of not mentioning a person's name for months or years after their death [1].

\footnotetext{
15 http://inhabitat.com/6-green-designs-for-the-grave/nadine-jarvis-pencil/

${ }^{16}$ http://www.scanmemories.org/fullscreen.html
} 
Haverinen describes ritual qualities in an online 'fly-past' in Second Life, performed with virtual aircraft in memory of a 13 year-old gamer who died of leukemia [16]. The digital memorial ThanatoFenestra [39] sits somewhere between the concrete and the performative, acting as both a physical concrete marker memorialising a dead relative and a form that explicitly supports ritualistic activity in which the act of lighting a candle becomes the important focus of activity. Increasingly, the digital environment offers "an unprecedented freedom to shape new and personal ...rites, and ... unexpected opportunities to express spiritual feeling" [2].

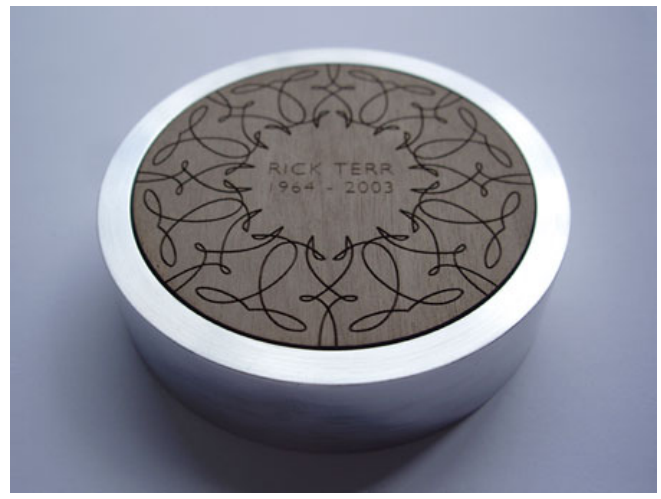

Figure 5: Access key to the digital remains of a deceased person $^{17}$.

\section{Static $\leftrightarrow \rightarrow$ Evolving}

The form of a memorial evolves over time, as its content is reformatted, augmented or degrades. How a memorial is experienced will also change as its initial audience move on from the experience of loss, or die out. A sensitive example of active evolution can be found in the aftermath of the Newtown USA massacre of children and adults in 2012. The town was inundated with public displays of sorrow and sympathy, expressed through spontaneous temporary memorials including flowers, teddies, and messages. After a period of time, and following consultation with the bereaved, these ephemeral items were removed, and then converted into a permanent memorial. Organic material like flowers were processed into "sacred soil", the teddy bears and other nonorganic items were turned into bricks and other building materials. Both will be incorporated in a more permanent memorial [37].

Passive evolution can occur through degradation. Weeds grow over graves, and headstones collapse and ultimately crumble if not tended to. Cemeteries often use such processes as markers for when a plot is conceivably reusable. When a grave becomes untended it implies that those who might remember the deceased have themselves now passed away, and therefore the natural lifecycle of memory and memorialization has moved on. The act of tending a grave can often act as a form of more abstract

\footnotetext{
${ }^{17}$ Photo: http://www.michelegauler.net/2006/07/15/digital-remains/
}

ritualistic memorialization. It is currently rare for digital memorials to degrade in this way. That is not to say however that digital memorials cannot evolve over time we are already seeing evolution through content addition. Mac Tonnies' website is indicative of some ways in which digital curation might happen post-mortem. In this case, a memorial has been crafted by adding content to a premortem website, from amongst the digital residua of a life that has passed [41]. Brubaker et al also highlight how the deceased's profile can grow on Facebook (if not memorialized), through active addition of images, tags, and evidence of SNS activities [5]. Some SNS users however, want their deceased network member's content to remain present but static, preserving a record of their relationship [19] exactly as it was - a preference realized, for example, through Facebook's memorialization option. This can raise tensions amongst the bereaved with differing opinions on the state in which an SNS presence should be left. Decisions made post-mortem on this state may become critical to the emergence of a digital postself, and making changes to a post-mortem account can be exceptionally difficult [25].

Memorials thus have the potential for evolution or stasis. Whilst this dimension is yet to be much used in the digital arena, it presents engaging and novel design opportunities, especially when issues of temporality and degradation are thrown into the mix. Moncur [26] has previously described how the life history of digital artifacts continues after user death, as new layers of metadata and meaning accrue. We assert that this argument extends to digital memorials. Even when a memorial is disassembled into component parts, each part may continue on - perhaps as a memorial in itself.

\section{WHAT MESSAGE SHOULD THE MEMORIAL CONVEY?}

Authors curate inputs, producing the digital memorial as output. We have already described the form which this output can take. We now move on to discuss the intentionality of the memorial - what message is it intended to convey, ranged along dimensions of cultural to personal, sacred to secular.

\section{Intentionality: Cultural $<->$ Personal}

The intention of the message conveyed by a memorial is deeply affected by its intended audience, as well as its author(s). Memorials may convey a message that is personal, making sense of loss, affirming the life of the deceased and creates a therapeutic space in which the continuing bonds between the living and the dead can be negotiated and sustained. In this context, digital technologies can present opportunities for the creation of memorials which deviate from mainstream culture and practice, delivering agency to those marginalized by subculture or type of bereavement [21]. Disenfranchised grief - such as that experienced by those who have been bereaved through a socially stigmatized illness such as AIDS - can be expressed where before their feelings may have been stifled. 
Memorials can also be used to communicate a broader cultural message. Rosetta Stone delivers a public-facing message which tries to reframe death in a positive context, highlighting the contribution that the dying make to society [35]. In deaths of aggression, memorials have been used to publicly allocate guilt, by highlighting the perpetrator (e.g. The National September 11 Memorial). Memorials have also been used to raise awareness of civic concerns, as seen with "Ghost bikes" 18 . These are bicycles that are painted white and locked to a street sign near the site of a fatal crash involving a cyclist. They serve both as memorials and as warnings of dangerous places for cyclists. In the context of genocide, Friedman has alluded to preserving knowledge through technology "to ensure that such atrocities do not occur again and to protect against revisionist histories" [14] (p2244). We have also seen unsavory memorials created with the intention of causing public offence - e.g. the use of an irreverent symbol representing the Twin Towers attack trended on Google through troll activity [28].

The presence of the dead in society, through their representations in public (often vernacular) memorials, can be the subject of divided opinion. Digital memorials can serve as a useful compromise when tensions arise over the sequestration of death. A good example here stems from the public memorial cairns placed on Scotland's highest mountain, Ben Nevis - often at the death site. These memorials resulted in debate over the appropriateness of their public nature in a much-loved recreational space. In response, the cairns were removed and an online memorial created where the bereaved could visit the site of the climber's death virtually ${ }^{19}$.

Public websites may themselves function as memorials, intentionally or unintentionally, and be grief-specific or non grief-specific [16,43]. For example, a genealogical website could be considered to be an intentional, non-grief specific website, whereas Banksophilia ${ }^{20}$, repurposing the author Iain Banks' autobiographical website to incorporate fans' messages of loss, is unintentional and reoriented to be griefspecific.

\section{Sacred $<->$ Secular}

Building on notions of grief-specific and non-grief specific and the intentional and unintentional, we can also place memorials on the dimension of sacred to secular. Some secular memorials merely mark spaces and sites of note, such as London's Blue Plaques. There is no assumption of deeper emotional meaning, but the act of placing a plaque is a signifier of importance - someone of note lived here, or something significant happened at this place. Whilst marking out a site in such a fashion renders the space as somewhat special, it is none-the-less a fairly prosaic form of memorial with limited emotional content. Equally, the

\footnotetext{
18 http://ghostbikes.org/

19 http://ben-nevis.com/memorials/memorials.php

20 http://friends.banksophilia.com/
}

residua of a life - diary entries, personal collections of things, MS Word files (to randomly name some items) - can all become markers of significance after the death of a loved one [18]. These items are significant yet mundane: while death lends them significance, they are none-the-less held as everyday items, sometimes curious and sometimes sentimental. However, as described variously above, many memorials are heavily laden with what we might consider a spiritual element, and are designed accordingly to provide impact to the observer (especially those framed within a religious context such as tombs in chapels of rest and Church crypts). Equally, the inclusion of human remains and other such devices of the reliquary invoke a sanctity and sacredness that it is hard to surpass. Technology and religion have often been uneasy bedfellows (with some religious traditions being directly antagonistic to technology), however, we are increasingly seeing the interplay between technology and spirituality [49]. This is increasingly opening up the design space for digital memorials to hold more sacred qualities. Currently however, there are precious few examples of sacred digital technologies, let alone sacred digital memorials.

\section{APPLYING THE FRAMING QUESTIONS}

In this paper, we have put forward a set of questions that can be used in designing digital memorials:

- Who are the actors involved in digital memorials?

- What are the inputs?

- What form does the memorial take?

- What message should the memorial convey?

Below we sketch out how some of these questions helped the second author to explore the conceptual design space for a specific memorial. The example is based on design explorations within the Spomenik project, which the second author ran from 2009-2011. In this project, in close collaboration with [anon] at [anon] Design, we were exploring concepts for the memorialization of victims of Stalinist purges in Slovenia (in the former Yugoslavia). These purges happened during the months following the end of WWII [9]. Growing up as part of a diaspora community of Slovenian émigrés, [anon] was keen to design a memorial that would raise consciousness amongst Slovenians of the number and extent of mass graves that had been left (often hidden) throughout the country.

Focusing on the questions above allows us to unpack some of the design decisions that were being explored. A focus on the actors involved suggested that the authors of the memorial were principally [anon], and those people in association who within the diaspora community had been collecting records of those who had died, and who had been mapping the mass grave locations. Analysis of the audience yielded fertile results. Originally, we had assumed that the audience would be an unsuspecting community of young Slovenians using mobile technology. We rapidly realized the importance of the memorial serving the wider diaspora 
community, who not only wanted their memories to be returned to their homeland, but also wanted to tacitly see evidence of those memories being interacted with by resident Slovenians; this processing showing that memory traces of the forgotten victims had been in effect 'restored'.

The inputs to the memorial were very simply framed as digitized data from the records kept of victims, and data pertaining to the GPS-recorded locations of the mass graves. This pushed us towards various design ideas around visualizing the enormity and scale of the tragedy, but also towards ideas which drew attention to the spatiality and the pervasiveness of the graves.

Suggested forms for the memorial were shaped by a desire to construct a mobile experience that allowed a pervasive connection to mass graves. We constructed concepts that involved a geo-map of the grave sites being 'relocated' and replayed over a city scape, such that one might stumble upon a digital 'grave' at the end of their street or at the corner of a city centre square, keeping the spatial relation of known sites intact but playing with the scale of their representation. This leveraged the very wide penetration of mobile (smart) technologies in Eastern Europe. It also let us begin to think about the nature of a digital memorial being something that can be repackaged and replayed, translating space and time such that the experiences might be removed from their original location. This is a feature little used in more traditional non-digital memorials, which often otherwise attempt to mark or sanctify very specific nontransient spaces. Herein we could play with scale, shrinking the map of sites down to a scale so that they could be experienced in a walking tour.

The message of the memorial needed to be one of commemoration, but focus on this aspect suggested that we must also work towards reconciliation in a complex political environment (this is after all still living memory for some in Slovenia). Equally, the memorial needed to be both personal and cultural. Our concepts utilized elements of scale to help frame the designs as a national monument (i.e. by showing the geographic spread of the atrocity and its pervasive nature throughout the country). At the same time, we worked with concepts of matching personal data of victims to memorial technology users, to foster empathy through similarity. This meant that we could also try to craft personal experiences with the message through the concept's design. Concepts we worked with also chose to invoke elements of the sacred, by utilizing well-rehearsed religious iconography from the region such as using grave candles as mapped markers of a virtual gravesite.

What we see through this analysis is the way in which these sensitizing questions can be used to pull focus on critical aspects of the design space, to interrogate our thinking as designers, and to enrich our concept work by systematically working through key variables of the 'memorial landscape'.

\section{DISCUSSION}

On first consideration, the concept of a digital memorial may appear highly tractable: closer inspection reveals its complex nature. In this paper, we have attempted to make this concept more manageable through the articulation of a set of characteristics, grouped into four categories: actors, inputs, form and message. At least one characteristic from each category is required in creating a digital memorial.

It is not our intention to be definitive in proposing a framework for digital memorials. Rather, we offer it up to delineate the breadth of design opportunities inherent to this space, and to promote reflection and innovation amongst the HCI community. Reference is made to the wider tradition of analog memorials to further enrich the discussion. The design of digital memorials represents an emergent space, and one that poses fresh challenges to technology designers. We anticipate others adding dimensions to the mix that might further elucidate the design-space and would welcome such additions. The framing questions serve to both inspire design but also to support critique. They can be used to interrogate a concept to see how proposals have responded to these critical challenges of defining and supporting relevant actors, and then justifying their choice of inputs, form and message.

The framework also serves a secondary purpose, as a marker in time and a sampling point to observe where we have come to in relation to the digitization of death. As our lives become increasingly digital and networked [9, 30], this overview of the ways in which digital technology intersects with some of the most fundamental features of 'civilized' life - i.e. the ways in which we memorialize helps us to evaluate the state of our nation(s) and to critically examine our attitudes to the emergent digital self.

This work, although not explicitly intended to do so, also helps to further the program of value sensitive design [4], critically examining the ways in which human values such as grief and mourning can be catered for in digital design.

\section{FUTURE WORK}

Ample opportunities for future work exist in this emergent space. Here, we highlight questions that have achieved salience for us through the process of writing this paper.

\section{Culture and Curation of the Postself}

The characteristics that we have defined are drawn from a Western perspective. Even within this, there is much variation - e.g. Dutch home shrines do not have direct parallels in the UK, as far as we are aware. We encourage the addition of further dimensions to digital memorials that reflect other cultural perspectives. Such an extension would provide a rich source of inspiration for designers.

One area which is deeply affected by culture is the concept of the postself, the socially constructed identity of the individual after death [47]. From our (Western) perspective, curation of the postself raises basic questions of what digital material to aggregate into a memorial, when there is 
so much and its nature can continue to change and develop even after a user's death [26]. How do we distil the appropriate physical and conceptual properties, from amongst the terabytes of data representing a life, event or place? One design opportunity is through the use of time capsules - an approach previously taken by [32]. Curation of the postself also stimulates questions of ownership. Who should have the right to create a digital memorial, to change or delete it? How should file management protocols evolve to support shared co-creation and co-curation of digital memorials [25]?

\section{Temporality}

Temporality presents rich opportunities in the context of digital memorials. We have seen that (non-digital) memorials may have ephemeral/ evolving qualities. How does this transfer to digital memorials? Whilst decay and degradation is the default in nature, perfection and stasis are the defaults in the digital environment. Action must be taken to effect digital change. So how do we program for decay and degradation? Wallace's provocative design work on digital lockets, where content was lost gradually over time, pixel by pixel, is one of few examples of how we may begin to address this question [42]. It is valid to consider whether decay is even desirable in digital memorials. Physical memorials redact physical space. Over generations they may get in the way as their significance fades, to the point that they are removed (at least in part) - e.g. to be replaced by a motorway ${ }^{21}$ - or reintegrated into the landscape as something quite different. How does this compare with digital, where space is not at a premium? Is loss of detail - or of the whole memorial - appropriate, desirable, engaging? This question of digital decay generalises beyond memorials, to all the data that we leave behind: its utility across time will vary widely [26].

\section{CONCLUSION}

As with many other forms of computer-mediated communication, memorialization is nothing new. As a species, we are expert at sharing information through a range of mechanisms: written, oral, visual, tangible. What is new is the use of digital as the vehicle, and its capabilities. Rewarding design opportunities exist in creating a remarkably broad range of digital memorials, situated within a tradition of memorialization that extends back to the earliest vestiges of human civilization.

\section{ACKNOWLEDGMENTS}

The authors acknowledge the financial support of the EPSRC (grant EP/I026304/1) and RCUK and Horizon Digital Economy Research (grant EP/G065802/1).

\section{REFERENCES}

1. Aboriginal and Torres Strait Islander Health Branch. Sad News, Sorry Business: Guidelines for caring for

\footnotetext{
21 http://wellington.govt.nz/recreation/gardens/bolton-street-memorialpark/history
}

Aboriginal and Torres Strait Islander people through death and dying. Queensland, Australia, 2013.

2. Altena, M. Agencies of the Afterlife: Weblogs and Television Shows on Death in the Netherlands. In D.R. Cooley and L. Steffen, eds., Re-imaging death and dying. Inter-disciplinary Press, Oxford, UK, 2009.

3. Auger, J. Speculative design: crafting the speculation. Digital Creativity 24, 1 (2013), 11-35.

4. Borning, A. and Muller, M.J. Next Steps for Value Sensitive Design. Proc. CHI 2012, ACM Press (2012), 1125-1134.

5. Brubaker, J.R., Hayes, G.R., and Dourish, J.P. Beyond the Grave: Interpretation and participation in perimortem behavior on Facebook. The Information Society 29, 3 (2013), 152-63.

6. Brubaker, J.R. and Hayes, G.R. "We will never forget you [online]": an empirical investigation of post-mortem myspace comments. Proc. $C S C W$ '11, ACM Press (2011), 123-132.

7. Castells, M. The rise of the network society: The information age: Economy, society, and culture. Vol. 1. Wiley \& Sons., 2011.

8. Cohen, E.L. One nation under radio: digital and public memory after September 11. New Media \& Society 6, 5 (2004), 591-610.

9. Corselis, J. and Ferrar, M. Slovenia 1945: Memories of Death and Survival after World War II. I B Tauris \& Co Ltd, 2010.

10. Durrant, A., Kirk, D., and Reeves, S. Human Values in Curating a Human Rights Media Archive. Proc CHI'14, ACM Press (2014).

11. Fitzpatrick, P. Objects at the Wall: Continuing Bonds and the Vietnam War Memorial: Grief \& Loss Expressed in the Objects Left at the Vietnam War Memorial Washington DC. Lambert Academic Publishing, 2012.

12. Foong, P.S. and Kera, D. Applying Reflective Design to Digital Memorials. Proc. SimTech'08, (2008).

13. Foot, K., Warnick, B., and Schneider., S.M. Web-Based Memorializing After September 11: Toward a Conceptual Framework. Journal of Computer Mediated Communication 11, 1 (2005), 72-96.

14. Friedman, B. and Nathan, L.P. Multi-lifespan information system design: a research initiative for the HCI community. Proc. CHI '10, ACM Press (2010), 2243-2246.

15. Hallam, E. and Hockey, J. Death, Memory and Material Culture (Materializing Culture). 2001.

16. Haverinen, A.E. Memoria Virtualis - death and mourning rituals in online environments. Unpublished thesis. 2013. 
17. Kirk, D., Wiesemes, R., Moore, A., and Kosem, J. Towards Pervasive Monuments. Proc. Digital Futures'10, (2010), 52-53.

18. Kirk, D.S. and Sellen, A. On human remains: Values and practice in the home archiving of cherished objects. ACM Trans. Comput.-Hum. Interact. 17, 3 (2010), 1-43.

19. Lingel, J. The Digital Remains: Social Media and Practices of Online Grief. The Information Society 29, 3 (2013), 190-195.

20. MacConville, U. Roadside memorials. Bereavement Care 29, 3 (2010), 34-36.

21. Maddrell, A. Online memorials: the virtual as the new vernacular. Bereavement Care 31, 2 (2012), 46-54.

22. Massimi, M. and Baecker, R.M. A death in the family: opportunities for designing technologies for the bereaved. Proc. CHI'10, ACM Press (2010), 18211830.

23. Massimi, M., Moncur, W., Odom, W., Banks, R., and Kirk, D. Memento Mori: Technology Design for the End of Life. Proc. CHI EA'12, ACM Press (2012), 2759-2762.

24. Massimi, M., Odom, W., Kirk, D., and Banks, R. HCI at the end of life: Understanding death, dying and the digital. Proc. CHI EA'10, ACM Press (2010), 44774480 .

25. Moncur, W., Bikker, J., Kasket, E., and Troyer, J. From Death to Final Disposition: Roles of Technology in the Post-Mortem Interval. Proc. CHI'12, ACM Press (2012), 531-540.

26. Moncur, W. Digital ownership across lifespans. In C. Garratini and D. Prendergast, eds., Ageing and the Digital Life Course. Berghahn Books, Forthcoming.

27. Moncur, W. The Emotional Wellbeing of Researchers: Considerations for Practice. Proc. CHI 2013, ACM Press (2013), 1883-1890.

28. Moore, M. Google Trends hit by 'trolls', 9/11 web stunt. The Telegraph, 2009. http://bit.ly/15xvTnv.

29. Mori, J. Memorialising day-to-day content: Bushfire affected communities. Proc. OZCHI '10, ACM Press (2010), 435-437.

30. Negroponte, N. Being Digital. Vintage Books, USA, 1995.

31. Odom, W., Banks, R., Kirk, D., Harper, R., Lindley, S., and Sellen, A. Technology heirlooms? Considerations for passing down and inheriting digital materials. Proc. CHI '12, ACM Press (2012), 337-346.

32. Petrelli, D., van den Hoven, E., and Whittaker, S. Making History: Intentional Capture of Future Memories. Proc. CHI'09, ACM Press (2009), 17231732.
33. Prendergast, D., Hockey, J., and Kellaher, L. Blowing in the wind? Identity, materiality, and the destinations of human ashes. Journal of the Royal Anthropological Institute 12, 4 (2006), 881-898.

34. Renfrew, C. and Bahn, P. Archaeology: Theories, Methods and Practice. Thames \& Hudson, UK, 2012.

35. Richards, N. Rosetta Life: Using Film to Create "Bearable Fictions" of People's Experiences of LifeLimiting Illness. In The Therapeutics of Death in Visual Culture. .

36. Riechers, A. The Persistence of Memory Online: Digital Memorials, Fantasy, and Grief as Entertainment. Human-Computer Interaction Series, (2013), 49-61.

37. Rivera, R. As Memorials Pile Up, Newtown Struggles to Move On. New York Times, 2013. http://nyti.ms/195f3da.

38. Shalev, A. Online visit to 'Palestinian Holocaust museum' - Israel Culture. YnetNews.com, 2009.

39. Uriu, D. and Okude, N. ThanatoFenestra: photographic family altar supporting a ritual to pray for the deceased. Proc. DIS'10, ACM Press (2010), 422-425.

40. Valentine, C. Continuing bonds after bereavement: a cross-cultural perspective. Bereavement Care 28, 2 (2009), 6-11.

41. Walker, R. Cyberspace When You're Dead. The New York Times Magazine, 2011. http://nyti.ms/16ctgEc.

42. Wallace, J. CraftCube:Locket. Digital Jewellery, 2010. http://www.digitaljewellery.com/jaynewallace/CraftCub e Locket.html.

43. Walter, T., Hourizi, R., Moncur, W., and Pitsillides, S. Does the internet change how we die and mourn? An overview. Omega: Journal of Death \& Dying 64, 4 (2012), 275-302.

44. Walter, T., ed. The Mourning for Diana. 1999.

45. Walter, T. The New Public Mourning. In M. Stroebe, R. Hansson, W. Schut and H. Stroebe, eds., Handbook of Bereavement Research and Practice: 21st century perspectives. Washington, DC: APA, 2008, 241-262.

46. Walter, T. Grief and culture. Bereavement Care 29, 2 (2010), 5-9.

47. Wojtkowiak, J. and Venbrux, E. House shrines in the Netherlands: From soul to postself: Home memorials in the Netherlands. Mortality 14, 2 (2009), 147-158.

48. Woodthorpe, K. Using bereavement theory to understand memorialising behaviour. Bereavement Care 30, 2 (2011), 29-32.

49. Wyche, S. and Griner, R. Extraordinary computing: religion as a lens for reconsidering the home. Proc. $\mathrm{CHI}$ '09, ACM (2009), 749-758. 